\title{
A Novel Method for Detection of Endo-Xyloglucan Transferase
}

\author{
Kazuhiko Nishitani \\ Department of Biology, College of Liberal Arts and Sciences, Kagoshima University, \\ Kagoshima, 890 Japan
}

\begin{abstract}
A new approach has been developed for quantification of the activity of endo-xyloglucan transferase, a novel enzyme that mediates the transfer of a segment of one xyloglucan molecule to another xyloglucan molecule. Purified xyloglucans with defined molecular-weight distributions and their fluorescent derivatives (pyridylamino xyloglucans) were used as substrates for the enzymatic reaction. The transferase activity was quantified by monitoring changes in molecularweight distributions of substrates by an alkali compatible gel permeation chromatographic system, equipped with a pulsed amperometric detector and a fluorescence detector. This new method was applied to the rapid detection and characterization of a novel transferase derived from plant tissues.
\end{abstract}

Key words: Cell wall - Endo-xyloglucan transferase - Pulsed amperometry detector Pyridylamino xyloglucan - Vigna angularis Ohwi et Ohashi (azuki bean) - Xyloglucan.

The plant cell wall is composed of crystalline microfibrils embedded in a matrix of amorphous polymers (Albersheim 1976, Fry 1988). Xyloglucans (XGs) are the major components of the matrix and function as cross-links between cellulose microfibrils, with resultant formation of an interwoven network structure, which provides the wall with viscoelastic properties (Talbott and Ray 1992a). Certain changes in the viscoelastic properties, which are achieved by chemical creepage (Cosgrove 1989), are required for the extension of cell walls and, hence, for cell growth (Masuda 1978, Cleland 1987). Several lines of evidence indicate that structural changes in XGs are involved in such chemical creepage in higher plants (Nishitani and Masuda 1981, 1982, 1983, Inouhe et al. 1984, Hoson et al. 1991). Although involvement of endo-glycosyltransferases in chemical creepage of the wall matrix was postulated almost two decades ago (Albersheim 1976), the existence of such enzymes has not yet been demonstrated. Recently, the existence of some enzyme responsible for transglycosylation between xyloglucan molecules was suggested by circumstantial evidence obtained independently by several research groups (Baydoun and Fry 1989, McDougall and Fry 1990, Nishitani and Tominaga 1991, Fry et al. 1992, Talbott and Ray 1992b). Furthermore, Nishitani and Tominaga (1991)

Abbreviations: EXT, endo-xyloglucan transferase; GPC, gel permeation chromatography; $\mathrm{PAD}$, pulsed amperometric detector; PA-, pyridylamino-; XG, xyloglucan. and Talbott and Ray (1992) suggested the involvement of a transferase in regulation of the molecular-weight distribution of xyloglucans in plant cell walls.

In apoplastic solutions isolated from the cell wall space of epicotyls of Vigna angularis, we detected an enzymatic activity that mediated an increase in the molecular weights of XGs in vitro (Nishitani and Tominaga 1991). The enzymatic reaction suggested the presence of an endoxyloglucan transferase (EXT) in the cell-wall space of the plant. A similar activity was also detected in tissue homogenates from other plants (Fry et al. 1992). The purification and characterization of this activity was, however, unsuccessful, in part because no suitable assay system specific for the transferase was available (Nishitani and Tominaga 1991, Fry et al. 1992). In order to characterize the EXT, we have developed a new assay system, using a fluorescent derivative of XG as the acceptor substrate and an alkalicompatible GPC system. Use of these new tools has made it possible to detect and quantify the activity of a transferase that catalyzes transfer of a large segment of XG from one XG molecule to another molecule to generate a chimeric or recombinant XG molecule. This new procedure was successfully exploited for the first purification of an EXT from plant tissues (Nishitani and Tominaga 1992).

\section{Materials and Methods}

Preparation of enzyme-A crude preparation of the 
apoplastic enzyme with EXT activity was obtained from epicotyls of dark-grown seedlings of Vigna angularis Ohwi et Ohashi cv. Takara by the previously reported method (Nishitani and Tominaga 1991). EXT was purified from the crude preparation as described elsewhere (Nishitani and Tominaga 1992).

Preparation of substrates-XGs extracted from cell walls of Vigna (Nishitani and Tominaga 1991) and tamarind (Tamarindus indica L.) (Fanutti et al. 1991) were further fractionated by GPC on a column $(16 \mathrm{~mm}$ i.d. $\times 500$ $\mathrm{mm}$ ) of Superose 6 prep (Pharmacia), with water as the eluent, for preparation of xyloglucans with defined molecular-weight distributions. The reducing ends of purified XGs from tamarind were coupled with 2-aminopyridine by reductive amination using sodium cyanoborohydride (Hase et al. 1979) to generate PA-XGs. The labeled XGs were fractionated and purified by GPC on Superose 6 prep with water as the eluent.

Enzymic reaction-Ten $\mu \mathrm{g}$ of non-labeled XGs from $V i g n a$ or tamarind were incubated in $10 \mu \mathrm{l}$ of $0.2 \mathrm{M}$ sodium acetate buffer (pH 5.8) that contained various amounts of the crude preparation of enzyme or the purified EXT, at $25^{\circ} \mathrm{C}$, for various periods of time. Alternatively, a mixture of $10 \mu \mathrm{g}$ of non-labeled XG and $2 \mu \mathrm{g}$ of PA-XG were used as substrate and were incubated with purified EXT under the same conditions.

HPLC - Changes in molecular weights of XGs during the enzymatic reaction were analyzed by GPC. The GPC system consisted of an alkali-stable non-metal pump (model GPM; Dionex, U.S.A.), a pulsed amperometric detector (PAD; Dionex), a fluorescence detector (model RF 535; Shimadzu, Japan) and columns of TSK gel G3000PW $(8 \mathrm{~mm}$ i.d. $\times 300 \mathrm{~mm}$, in a glass tube) and G5000PW $(8 \mathrm{~mm}$ i.d. $\times 300 \mathrm{~mm}$, in a glass tube) connected in series. The glass columns of TSK gels were specially manufactured by Toso (Tokyo, Japan). The operating parameters for the PAD were as follows: $\mathrm{E} 1,0.05 \mathrm{~V}$ for $480 \mathrm{~ms}$; $2,0.6 \mathrm{~V}$ for $120 \mathrm{~ms}$; E3, $-0.6 \mathrm{~V}$ for $60 \mathrm{~ms}$; pulse duration range switch set at position 2; response time, $1 \mathrm{~s}$. For detection of PA$X G$ s by the fluorescence detector, an excitation wavelength of $320 \mathrm{~nm}$ and an emission wavelength of $400 \mathrm{~nm}$ were used. Samples were injected after having been dissolved in $20 \mu \mathrm{l}$ of a $0.1 \mathrm{M}$ solution of sodium hydroxide. The columns were eluted with a $30 \mathrm{mM}$ solution of sodium hydroxide that contained $15 \mathrm{mM}$ sodium acetate, at a flow rate of

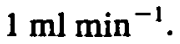

Molecular-weight calibration-Pullulans (mol wts, $853,000,380,000,186,000,100,000,48,000,23,700$, $12,300,5,800$ and $1,810 \mathrm{Da}$ ) were manufactured by Hayashibara Biochemical Laboratories (Japan). Maltooligomers (mol wts, 667 and $342 \mathrm{Da}$ ) and glucose were obtained from Seikagaku Corp. (Japan). These carbohydrates were used as markers for GPC. By measuring peak areas of individual carbohydrates, as detected by the PAD, we were able to evaluate responsiveness of the PAD to different carbohydrates relative to its response to glucose.

\section{Results and Discussion}

Gel-permeation chromatography-Figure 1 shows the relationship between $\log _{10}(\mathrm{~mol} w \mathrm{w})$ and elution volume of authentic carbohydrates passed through columns of TSK gels $5000 \mathrm{PW}$ and $3000 \mathrm{PW}$ connected in series. A mostly linear relationship between the two parameters was observed over a range of molecular weights from 853,000 to $180 \mathrm{Da}$.

Figure 2 shows the relative responsiveness of the PAD to individual carbohydrates with different molecular weights. The PAD response per unit weight of carbohydrate, which was defined as PAD responsiveness, declined rapidly as the mol wt increased from 180 to 5,800 . However, the PAD responsiveness to large polymers ( $\mathrm{mol}$ wts, 853,000 to $12,300 \mathrm{Da}$ ) was almost constant. Thus, the PAD

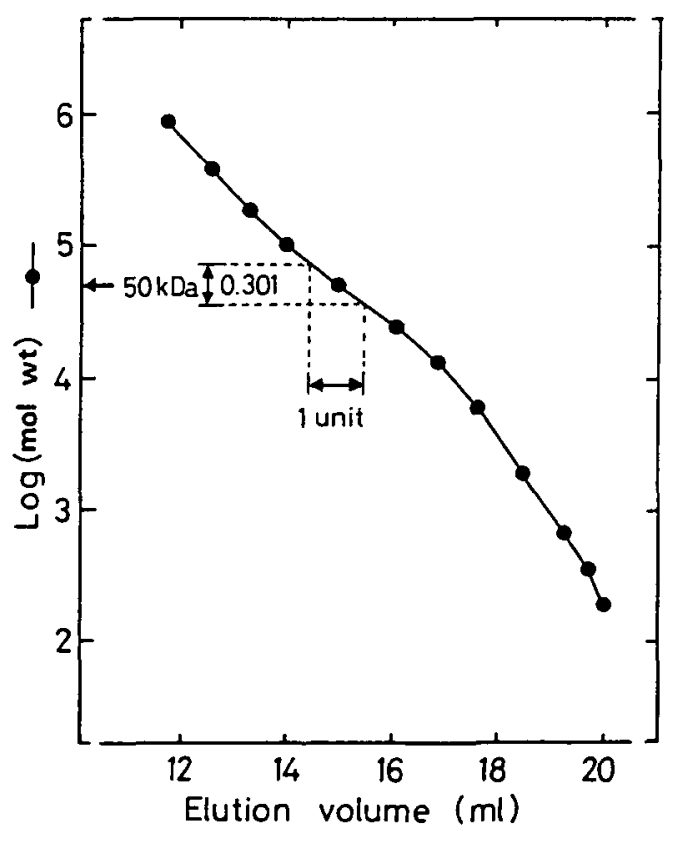

Fig. 1 Relationship between $\log _{10}$ ( $\mathrm{mol} \mathrm{wt}$ ) and elution volume of carbohydrates. Ten $\mu \mathrm{g}$ each of pullulans ( $\mathrm{mol} \mathrm{wts}, 85,300$ $1,810 \mathrm{Da}$ ) and maltooligomers (mol wts, 667 and $342 \mathrm{Da}$ ) and glucose were individually chromatographed on columns of TSK G5000PW and G3000PW connected in series and detected by PAD under the conditions described in Materials and Methods. The elution volume of each compound was recorded. $\log _{10}$ (mol wt) of each carbohydrate is shown as a function of elution volume. Arrows indicate a distance $\left(0.301=\log _{10}(2)\right)$ on the ordinate and the corresponding elution volume $(1.07 \mathrm{ml})$ on the abscissa. This elution volume was defined as 1 unit of peak width for 50$\mathrm{kDa}$ polymers (see Results and Discussion). 
response can be used as a measure of the total polysaccharide content of the eluate.

The response of the fluorescence detector was proportional to the number of PA-XG molecules because the reducing end of each $X G$ was tagged with a single pyridylamino group. Less than $10 \mu \mathrm{g}$ of XG or 20 pmole of PA-XG were required for analysis of the distribution of molecular weight by GPC under our conditions.

Peak broadening-Ten $\mu \mathrm{g}$ of non-labeled XG were incubated with $1 \mu \mathrm{g}$ of the crude preparation of apoplastic enzyme. Analysis of the reaction products by GPC revealed that the enzymatic reaction caused broadening of the peak of XGs without any change in the elution volume associated with the top of the peak. The broadening of the peak indicates that the enzymatic action generated both higherand lower-molecular-weight species of XG molecules by transglycosylation between XG molecules (Fig. 3).

The broadening of the peak caused by the crude preparation of enzyme was accompanied by generation of monosaccharides (the arrow a in Fig. 3). By contrast, no monosaccharides or oligomers were produced when XG was incubated with the purified EXT, which also mediated broadening of the peak (Fig. 4). Clearly, the monosaccharides were liberated by the action of hydrolases present in the crude preparation of the enzyme and not by the action of EXT. Thus, the peak broadening reflects the transglycosylation reaction that is catalyzed by EXT. Extended incubation for several hours with the crude enzyme caused degradation of high-molecular-weight XGs and interfered

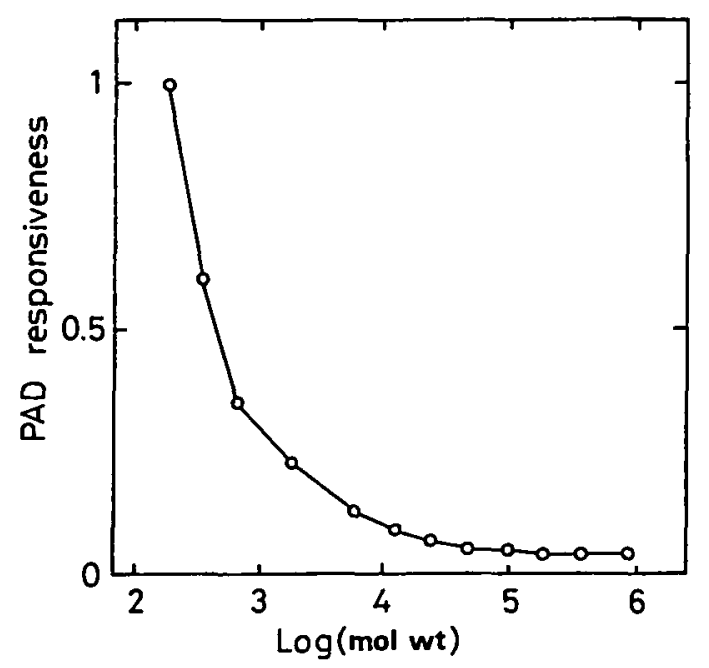

Fig. 2 Relationship between $\log _{10}$ ( $\mathrm{mol} w \mathrm{t}$ ) and responsiveness of the PAD to carbohydrates. Carbohydrates with various molecular weights were chromatographed as described in the legend to Fig. 1 and the peak area for individual carbohydrate samples relative to that of glucose was calculated and expressed in terms of PAD responsiveness (see also text).

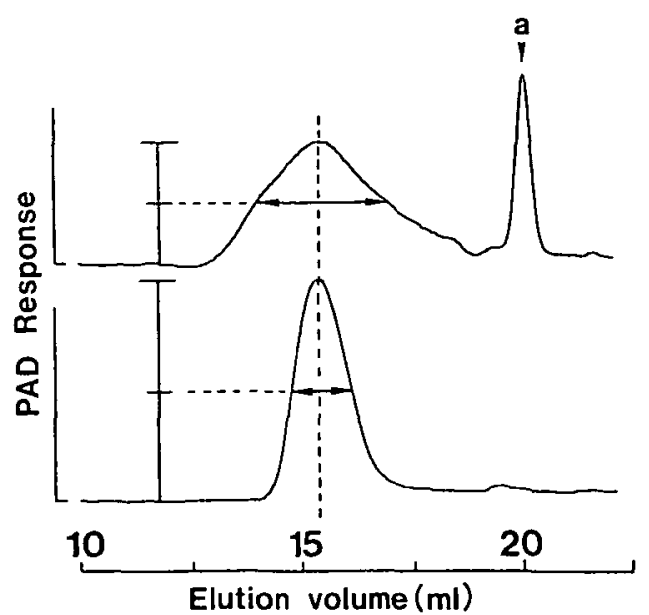

Fig. 3 Changes in molecular-weight distributions of XGs mediated by a crude preparation of EXT. Ten $\mu \mathrm{g}$ of non-labeled $\mathrm{XGs}$ from Vigna (mol wt, $65 \mathrm{kDa}$ ) were incubated with $1 \mu \mathrm{g}$ of a native (upper panel) or denatured (lower panel) crude preparation of enzyme derived from the apoplast of Vigna epicotyls in 10 $\mu \mathrm{l}$ of $0.2 \mathrm{M}$ sodium acetate, $\mathrm{pH} 5.8$ for $1 \mathrm{~h}$ at $25^{\circ} \mathrm{C}$. After the reaction, the reaction mixture was analyzed by GPC under the conditions described in the legend to Fig. 1. The width halfway to the top of each peak of polymer was measured, expressed in $\mathrm{ml}$ and defined as the peak width. Arrow a indicates monosaccharide peak.

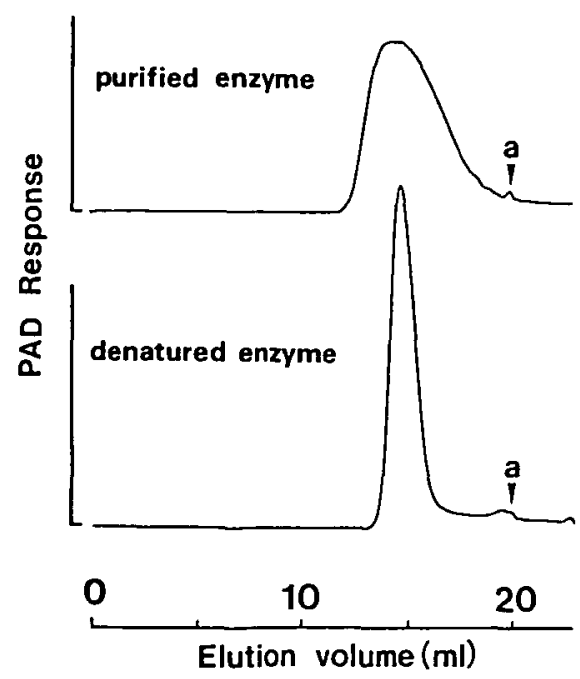

Fig. 4 Changes in the distribution of molecular weights of XGs mediated by a purified EXT. Ten $\mu \mathrm{g}$ of non-labeled XG from Vigna (mol wt, $65 \mathrm{kDa}$ ) were incubated with $40 \mathrm{ng}$ of purified EXT derived from the apoplast of Vigna epicotyls for $1 \mathrm{~h}$ under the conditions described in the legends to Fig. 3. Products of the reaction were analyzed by GPC under the conditions described in the legend to Fig. 1. Notice the reduced size of the peak of monosaccharides, indicated by arrow a (cf. Fig. 3). 


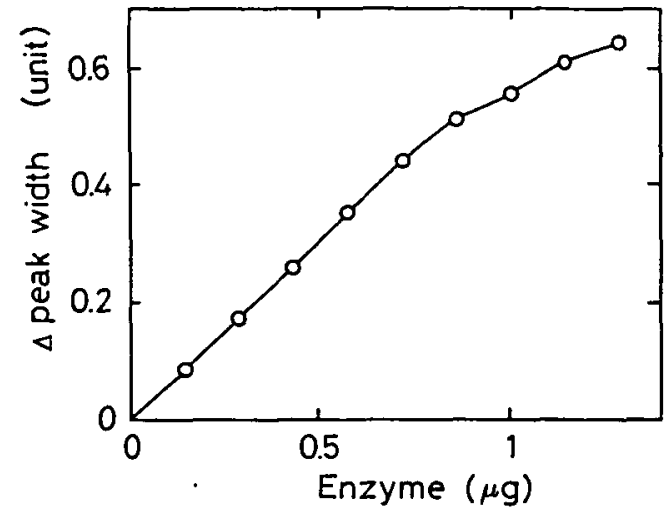

Fig. 5 Relationship between the dose of enzyme and the increase in the peak width. Ten $\mu$ g of XGs ( $\mathrm{mol} \mathrm{wt}, 65 \mathrm{kDa}$ ) were incubated with various amounts of crude preparation of apoplastic enzyme for $\mathbf{3 0} \mathrm{min}$ under the conditions described in the legend to Fig. 3. After the products of the reaction had been fractionated by GPC, increases in the widths of peaks of XGs were measured and expressed in peak width units by the procedure described in Results and Discussion.

with the peak broadening mediated by EXT.

To quantify the degree of broadening we measured the peak width halfway to the top of the chromatogram and expressed the width in terms of the elution volume (in ml; Fig. 3). In an ideal normal distribution curve, the peak width half way to the top of the peak is a function of its standard deviation (the peak width $=2.35 \times$ standard deviation). Thus, the peak width provides an appropriate measure of the pattern of distribution of material and is independent of the total area of the peak. In the present study,

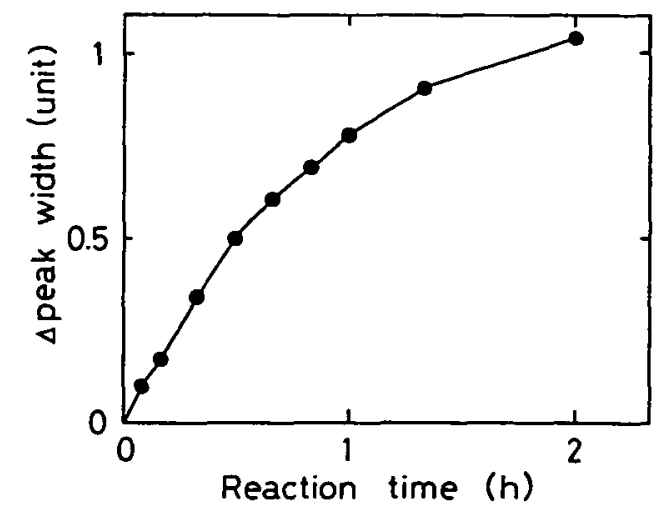

Fig. 6 Changes in peak width as a function of incubation time. Ten $\mu \mathrm{g}$ of XG were incubated with $1 \mu \mathrm{g}$ of the crude preparation of enzyme for $1 \mathrm{~h}$ under the conditions described in the legend to Fig. 3 for various periods of time. The enzymatic activity was expressed in peak width units, as described in the legend to Fig. 5. we have defined one unit of peak width as the elution volume that corresponds to a $\log _{10}(\mathrm{~mol} \mathrm{wt})$ of 0.301 on the ordinate in Figure 1. We employed the value $0.301 \quad\left(=\log _{10}\right.$ 2), because it corresponds to a two-fold difference in molecular weight. When we use $50-\mathrm{kDa} X \mathrm{X}$, for example, as the substrate, one unit of peak width is calculated to be $1.07 \mathrm{ml}$ from the diagram in Figure 1.

The EXT-mediated increase in the peak width was proportional to the dose of enzyme between 0 to 0.5 units (Fig. 5). Figure 6 shows that the peak width increased linearly during the first $30 \mathrm{~min}$ of the enzymatic reaction. These data show that peak broadening, as expressed in these units, is an appropriate measure of the transglycosylation reaction mediated by EXT.

Transfer of label-We used PA-XG as the acceptor molecule to quantify and characterize the transglycosylation reaction. PA-XG was prepared by tagging the reducing ends of XG molecules with a pyridylamino group, which is fluorescent. A mixture of 20 pmole of $500-\mathrm{kDa}$ non-labeled $\mathrm{XG}(10 \mu \mathrm{g})$ and 200 pmole of 10-kDa PA-XG (2 $\mu \mathrm{g})$ was used as the substrate for the enzyme reaction. These two substrates were resolved by GPC and detected by PAD (peaks $a$ and $b$ in Fig. 7). Transfer of XG segments from non-labeled XGs (donor) to PA-XGs (acceptor) was assessed by detection of high-molecular-weigh fluorescent XGs by GPC (peak $A$ in Fig. 7). The result clearly indicates that EXT mediates transfer of a high-molecular-weight XG segment from the $500-\mathrm{kDa}$ XG molecule to the $10-\mathrm{kDa}$ PA-
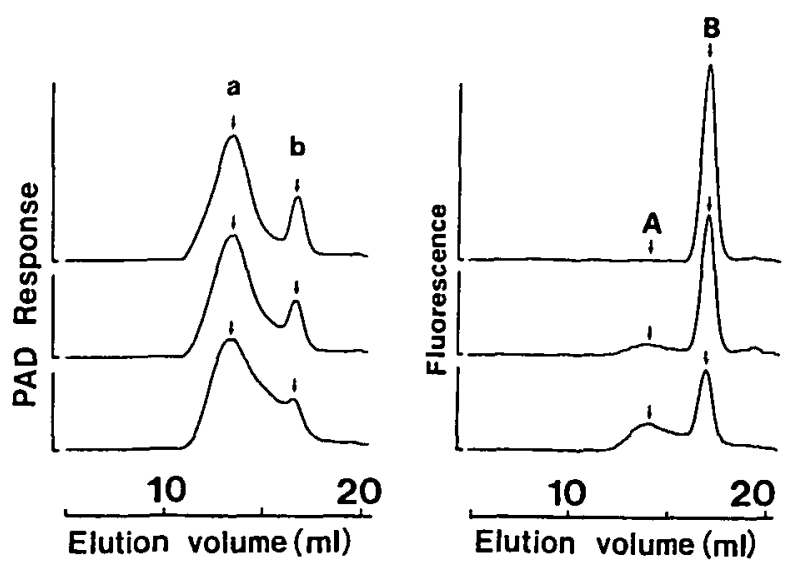

Fig. 7 GPC profiles of XG showing transfer of XG segments from non-labeled high-molecular-weight $X G$ to low-molecularweight PA-XG. A mixture of $10 \mu \mathrm{g}$ of non-labeled XG from Vigna (mol wt, $500 \mathrm{kDa}$ ) (arrow a) and $2 \mu \mathrm{g}$ of PA-XG (mol wt, $10 \mathrm{kDa}$ ) (arrows $\mathrm{b}$ and $\mathrm{B}$ ) was incubated with $0 \mathrm{ng}$ (upper panels), $10 \mathrm{ng}$ (middle panels) or $30 \mathrm{ng}$ (lower panels) of purified EXT for $1 \mathrm{~h}$ under the conditions described in the legend to Fig. 3. The products of the reaction were analyzed by GPC. Total XGs in the eluate were detected by a PAD, while PA-XG was detected by a fluorescence detector. 
XG molecule. Since the response of the fluorescence detector is proportional to the number of PA-XG molecules, the amount of high-molecular-weight PA-XG can be evaluated by measuring the area of peak $A$. The amount of highmolecular-weight PA-XG generated during a 1-h reaction was proportional to the amount of EXT present in the reaction mixture (Fig. 8). Thus, the amount of high-molecularweight PA-XG is also a suitable measure of EXT activity.

Ten ng of EXT caused production of 22.4 pmole of high-molecular-weight PA-XG during incubation at $25^{\circ} \mathrm{C}$ for $1 \mathrm{~h}$ (Fig. 8). The initial reaction mixture contained 20 pmole of 500-kDa XG and 200 pmole of 10-kDa PA-XG. Accordingly, generation of 20 pmole of the high-molecular-weight PA-XG indicates that each 500-kDa XG molecule has undergone transglycosylation reaction 1.12 times, on average, during the incubation.

Investigations of the substrate specificity of EXT showed that the donor substrate activity depends on the molecular weight of donor substrates. Reactions catalyzed by EXT occur more rapidly when donor substrates with higher molecular weight are used (Nishitani and Tominaga 1992). Little or no transglycosylation is observed when $X G$ s of less than $10 \mathrm{kDa}$ are used as donor substrates. However, XG oligomers as small as $1 \mathrm{kDa}$ can act as acceptors in the transglycosylation reaction. In the present study, no PA-XG smaller than $10 \mathrm{kDa}$ was produced during the enzymatic reaction, as shown in Figure 7 , indicating that EXT did not mediate the transfer of segments from $10-\mathrm{kDa}$ XG to 500-kDa XG. This result is consistent with the sub-

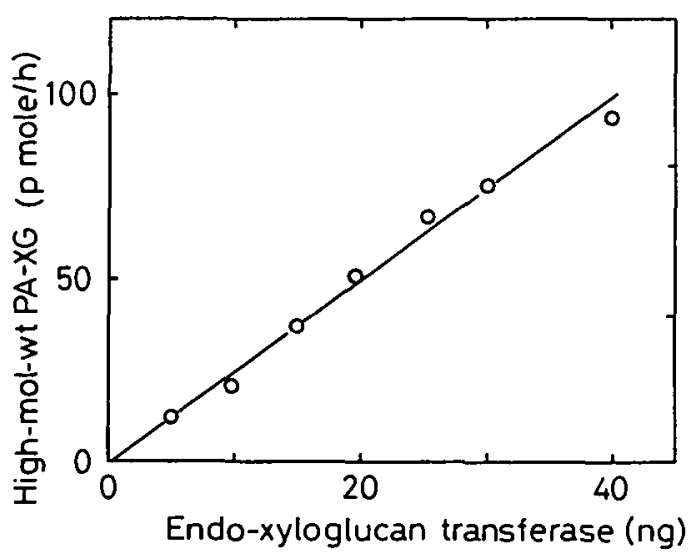

Fig. 8 Relationship between dose of EXT and production of high-molecular-weight PA-XG. A mixture of $10 \mu \mathrm{g}$ of non-labeled XGs from Vigna (mol wt, $500 \mathrm{kDa}$ ) and $2 \mu \mathrm{g}$ of PA-XG ( $\mathrm{mol} \mathrm{wt}, 10 \mathrm{kDa}$ ) was incubated with various amounts of purified EXT for $1 \mathrm{~h}$ under the conditions described in the legend to Fig. 3. The products of the reaction were analyzed by GPC, and the amount of high-molecular-weight PA-XG was calculated from the area (cf. peak $A$ in Fig. 7) and expressed in pmole as a function of the dose of enzyme. strate specificity of EXT (Nishitani and Tominaga 1992).

To examine the relationship between the rate of production the high molecular weight PA-XGs and the degree of peak broadening, as expressed in peak width units, the two experiments were conducted under the same conditions. Figure 9 shows the linear relationship between the two parameters, an indication that both parameters represent the transferase activity appropriately.

In conclusion, the results of the present study indicate that the activity of EXT is easily detected and quantified either (1) by measuring the distribution of molecular weights of XGs by GPC in a system equipped with a PAD or (2) by measuring changes in molecular weights of the PA-XG by GPC in a system equipped with a fluorescence detector as well as a PAD. Application of these new procedures has made it possible to detect and quantify EXT activity in $\mathbf{2 0} \mathrm{min}$ without using any radioactivity. These procedures have been successfully applied for purification of EXT for the first time (Nishitani and Tominaga 1992) and also for characterization of the mode of action of this enzyme. With other polysaccharides and their pyridylamino derivatives as substrates, this new method offers the opportunity for a new approach to the search for unknown transglycosylases that may be involved in the construction and modification of the architecture of the plant cell wall.

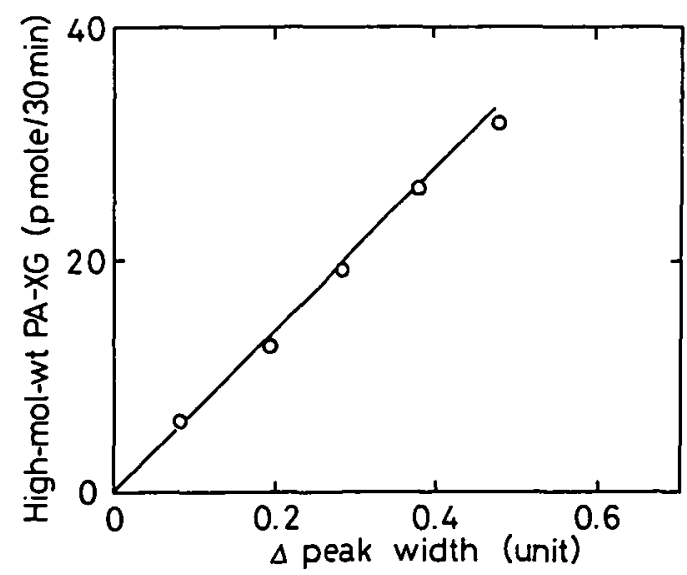

Fig. 9 Relationship between the production of high-molecularweight PA-XG and the increase in the peak width. A mixture of $10 \mu \mathrm{g}$ of non-labeled XG from Vigna (mol wt, $500 \mathrm{kDa}$ ) and 2 $\mu \mathrm{g}$ of PA-XG ( $\mathrm{mol} \mathrm{wt}, 10 \mathrm{kDa}$ ) was incubated with various amounts of purified EXT for $30 \mathrm{~min}$ under the conditions described in the legend to Fig. 3. The amount of high-molecularweight PA-XG generated during the enzyme reaction was determined by the procedure described in the legend to Fig. 8. For measurement of the increase in the peak width, $10 \mu \mathrm{g}$ of XGs from Vigna (mol wt, $65 \mathrm{kDa}$ ) was incubated with various amounts of purified EXT for $30 \mathrm{~min}$ under the same conditions described in the legend to Fig. 3. 
The author wish to thank Professor Susumu Hizukuri and Dr. Yasuhito Takeda (Kagoshima University) for providing pullulans. This work was supported by a Grant-in-Aid for Scientific Research (no. 03804055) from the Ministry of Education, Science and Culture, Japan.

\section{References}

Albersheim, P. (1976) The primary cell wall. In Plant Biochemistry. Edited by Bonner, J. and Varner, J.E. pp. 225-274. Academic Press, New York.

Cosgrove, D.J. (1989) Characterization of long-term extension of isolated cell walls from growing cucumber hypocotyls. Planta 177: $121-130$.

Cleland, R.F. (1987) The mechanism of wall loosening and wall extension. In Physiology of Cell Expansion During Plant Growth. Edited by Cosgrove, D.J. and Knievel, D.P. pp. 18-27. The American Society of Plant Physiologist, Rockville.

Baydoun, E.A-H. and Fry, S.C. (1989) In vitro degradation and extracellular polymer-binding of xyloglucan nonasaccharide, a naturally occurring anti-auxin. J. Plant Physiol. 134: 453-459.

Fanutti, C., Gidley, M.J. and Reid, J.S.G. (1991) A xyloglucanoligosaccharide-specific $a$-D-xylosidase or exo-oligoxyloglucan$a$-xylohydrolase from germinated nasturtium (Tropaeolum majus L.) seeds. Planta 184: 137-147.

Fry, S.C. (1988) The Growing Plant Cell Wall. pp. 219-249. John Wily \& Sons, Inc., New York.

Fry, S.C., Smith, R.C., Renwick, K.F., Martin, D.J., Hodge, S.K. and Matthews, K.J. (1992) Xyloglucan endotransglycosylase, a new wall-loosening enzyme activity from plants. Biochem. J. 282: 821-828.

Hase, S., Hara, S. and Matsushima, Y. (1979) Tagging of sugars with a fluorescent compound, 2-aminopyridine. J. Biochem. 85: 217-220.

Hoson, T., Masuda, Y., Sone, R. and Misaki, A. (1991) Xyloglucan antibodies inhibit auxin-induced elongation and cell wall loosening of azuki bean epicotyls but not of oat coleoptiles. Plant Physiol. 96: 551-557.

Inouhe, M., Yamamoto, R. and Masuda, Y. (1984) Auxin-induced changes in the molecular-weight distribution of cell wall xyloglucans in Avena coleoptiles. Plant Cell Physiol. 25: 13411351.

Masuda, Y. (1978) Auxin-induced cell wall loosening. Bot. Mag. Tokyo, special Issue 1: 103-132.

McDougall, G.J. and Fry, S.C. (1990) Xyloglucan oligosaccharides promote growth and activate cellulase: evidence for a role of cellulase in cell expansion. Plant Physiol. 93: 1042-1048.

Nishitani, K. and Masuda, Y. (1981) Auxin-induced changes in the cell wall structure: changes in the sugar compositions, intrinsic viscosity and molecular weight distributions of matrix polysaccharides of the epicotyl cell wall of Vigna angularis. Physiol. Plant. 52: 482-494.

Nishitani, K. and Masuda, Y. (1982) Acid pH-induced changes in the cell wall xyloglucans in Vigna angularis epicotyl segments. Plant Sci. Lett. 28: 87-94.

Nishitani, K. and Masuda, Y. (1983) Auxin-induced changes in the cell wall xyloglucans: effects of auxin on the two different subfractions of xyloglucans in the cell wall of Vigna angularis. Plant Cell Physiol. 24: 345-355.

Nishitani, K. and Tominaga, R. (1991) In vitro molecular weight increase in xyloglucans by an apoplastic enzyme preparation from epicotyls of Vigna angularis. Physiol. Plant. 82: 490-497.

Nishitani, K. and Tominaga, R. (1992) Endo-xyloglucan transferase, a novel class of glycosyltransferase that catalyzes transfer of a segment of xyloglucan molecule to another xyloglucan molecule. J. Biol. Chem. 267: 21058-21064.

Talbott, L.D. and Ray, P.M. (1992a) Molecular size and separability features of pea cell wall polysaccharides. Plant Physiol. 98: 357-368.

Talbott, L.D. and Ray, P.M. (1992b) Changes in molecular size of previously deposited and newly synthesized pea cell wall matrix polysaccharides. Plant Physiol. 98: 369-379.

(Received February 28, 1992; Accepted September 28, 1992) 